\title{
MOVIMENTOS DE MIGRAÇÃO E DISPERSÃO DE ADULTOS DA CIGARRINHA-DAS-PASTAGENS 1
}

\author{
EDISON RYOITI SUJIII ${ }^{2}$ MARIA ALICE GARCIA ${ }^{3}$ e ELIANA MARIA GOUVEIA FONTES ${ }^{4}$
}

\begin{abstract}
RESUMO - O efeito do movimento de adultos da cigarrinha-das-pastagens (Deois flavopicta Stal) em sua dinâmica populacional foi avaliado em pastagens de Brachiaria ruziziensis na região do Distrito Federal, Brasil. Foram utilizados painéis de plástico com cola adesiva para monitorar as taxas de movimentação. Os dados sugerem a ausência de um padrão predominante de movimentação em relação à posição geográfica das armadilhas. A ocorrência de vegetação baixa, semelhante às pastagens em volta da área estudada, aparentemente favoreceu a dispersão, ao passo que a ocorrência de cerrados ou matas na vizinhança inibiu o movimento nesta direção e aumentou a taxa de retorno da cigarrinha às pastagens. $\mathrm{O}$ inseto se deslocou principalmente mediante saltos ou vôos curtos e baixos (abaixo de $1 \mathrm{~m}$ ). Uma proporção aproximada de 4:1 (macho:fêmea) foi capturada nas armadilhas, indicando que os machos movimentam-se mais que as fêmeas. A velocidade média de movimentação, de populações marcadas com pó fluorescente atóxico e recapturadas após períodos variáveis de liberação, foi inferior a $5 \mathrm{~m}$ por dia. O movimento de dispersão de adultos não contribui significativamente para a perda ou recrutamento de adultos em populações de $D$. flavopicta, a não ser em casos de explosões populacionais ou extinção local.
\end{abstract}

Termos para indexação: Insecta, Homoptera, Cercopidae, padrão de vôo, dinâmica populacional, Deois flavopicta.

\section{MOVEMENTS OF MIGRATION AND DISPERSION OF ADULT SPITTLEBUGS}

\begin{abstract}
The effect of adults of the spittlebug (Deois flavopicta Stal) movement in their population dynamics was evaluated in pastures of Brachiaria ruziziensis in Brasília, DF, Brazil. Plastic panels containing adesive trap were used to monitorate the movement rates. The data suggest a lack of pattern related to the geographical position of the traps. Vegetation landscapes similar to pastures fields around the study area seemed to favour the dispersion, whilst Cerrados or wood vegetation in the neighborhood inhibted insect dispersion toward this direction and increased return rate of spittlebugs to the pasture. Spittlebugs moved mainly by short, low jumping flights (bellow $1 \mathrm{~m}$ ). A proportion of 4:1 male:female was captured in the traps, indicating that males move more than females. The movement of marked and recaptured populations was monitored with non-toxic fluorescent powder. Speed rates lower than $5 \mathrm{~m} /$ day was observed. Adult dispersion movement, apparently, does not contribute significantly to the loss or recruitment of individuals to populations of D. flavopicta. Consequently, there is no need to consider this movement in modeling this insect population dynamics. Migration may have a role in this dynamics except in some cases, such as outbreaks and local extinction.
\end{abstract}

Index terms: Insecta, Homoptera, Cercopidae, flight pattern, population dynamics, Deois flavopicta.

\footnotetext{
1 Aceito para publicação em 27 de maio de 1999.

${ }^{2}$ Eng. Agrôn., Ph.D., Embrapa-Centro de Pesquisa de Recursos Genéticos e Biotecnologia (Cenargen), Caixa Postal 02372, CEP 70849-970 Brasília, DF. E-mail: sujii@ cenargen.embrapa.br

${ }^{3}$ Biól., Ph.D., Dep. de Zoologia, IB, Universidade Estadual de Campinas (UNICAMP), Caixa Postal 6109, CEP 13083-970, Campinas, SP.

${ }^{4}$ Biól., Ph.D., Embrapa-Cenargen.
}

\section{INTRODUÇão}

Adultos de cigarrinhas-das-pastagens possuem boa capacidade de vôo a longa distância. Nilakhe \& Buainain (1988) estimaram que um indivíduo da espécie Deois flavopicta (Stal) (Homoptera; Cercopidae) pode percorrer $910 \mathrm{~m}$ em um único vôo, sendo capaz de voar por mais de $3 \mathrm{~km}$ sob condi- 
ções meteorológicas favoráveis. Apesar disso, $80 \%$ a $95 \%$ das cigarrinhas movimentam-se por meio de saltos curtos e baixos (até $1 \mathrm{~m}$ de altura) e apenas quando perturbadas (Menezes et al., 1983; Nilakhe \& Buainain, 1988). Aparentemente, tal comportamento caracteriza um movimento de dispersão em que a população altera o seu padrão de distribuição espacial aumentando a distância entre os indivíduos dentro de uma área de ocorrência (Rabb \& Stinner, 1978; Nilakhe \& Buainain, 1988). Dessa forma, é razoável supor que o principal padrão de movimento de adultos da cigarrinha seja de dispersão, enquanto apenas uma reduzida parcela da população estaria deixando o local por migração.

Por sua vez, o aparecimento súbito de adultos em pastagens onde ocorria pouca ou nenhuma ninfa (Fontes et al., 1995), a redução brusca na densidade de adultos (decréscimo da ordem de seis ou sete vezes em 24 horas) (Nilakhe \& Buainain, 1988) e a infestação em campos de cultivo de arroz e milho (Santos et al., 1982; Carneiro \& Cunha, 1984; Nilakhe et al., 1984), nos quais as ninfas do inseto não são capazes de se estabelecer, sugerem que o movimento migratório de populações de adultos não são eventos raros e podem influenciar a dinâmica populacional (Nilakhe \& Buainain, 1988; Sujii, 1994; Fontes et al., 1995).

O presente estudo objetivou observar os padrões de movimentação de adultos da cigarrinha-das-pastagens (D. flavopicta), em pastagens de Brachiaria ruziziensis Stapf (Poaceae) na região do Distrito Federal e entender como fatores ambientais podem afetar esses padrões, influenciando a dinâmica de populações locais na região.

\section{MATERIAL E MÉTODOS}

\section{Entrada e saída de adultos da pastagem}

As taxas de entrada e saída de adultos de $D$. flavopicta de uma pastagem de B. ruziziensis foram avaliadas a partir da instalação de 15 estações de coleta com armadilhas do tipo painel, em dezembro de 1995 e fevereiro de 1996. A pastagem medindo 3,1 ha apresentava plantas com porte que variou entre 0,25 e $0,50 \mathrm{~m}$ e densidade média de 10 e 15 adultos $/ \mathrm{m}^{2}$ em dezembro e fevereiro respectivamente. Ela está localizada na área experimental da EmbrapaCentro de Pesquisa Agropecuária dos Cerrados (CPAC), na região de Planaltina ao norte do Distrito Federal e faz divisa com outras pastagens da mesma espécie a norte e a leste, uma pastagem de Andropogon gayanus a oeste e uma área de cerrado freqüentemente perturbada pelo pastejo de gado bovino ao sul. As estações foram distribuídas ao acaso em número de três em cada cerca lateral da pastagem, sendo a disposição de cada uma delas vinculada ao respectivo ponto cardeal e outras três foram distribuídas ao acaso dentro da pastagem como controle. Cada estação de coleta era constituída de duas armadilhas instaladas, lado a lado, em diferentes alturas. As armadilhas constavam de painéis de captura com $1 \mathrm{~m}$ de largura por 1,2 $\mathrm{m}$ de altura constituídos de filme plástico transparente $(0,10 \mathrm{~mm}$ de espessura), recobertos com um adesivo Tangle trap, tanto na face voltada para o lado de dentro da pastagem como do lado de fora.

As alturas em que os painéis foram armados basearam-se em estudos anteriores desenvolvidos por Nilakhe \& Buainain (1988), que determinaram que o inseto movimenta-se a curta distância, principalmente mediante saltos curtos (até $6 \mathrm{~m}$ de comprimento) e baixos (aproximadamente $1 \mathrm{~m}$ de altura). A movimentação por distâncias maiores ocorre em vôos mais altos que podem alcançar até 5 ou $6 \mathrm{~m}$ de altura. Desta forma, parte dos painéis foram instalados no nível do solo, para interceptar insetos voando até $1,2 \mathrm{~m}$ de altura. $\mathrm{O}$ restante foi instalado a $1,2 \mathrm{~m}$, interceptando insetos voando até $2,4 \mathrm{~m}$ de altura. Tais coletas permitiram avaliar a movimentação a curta e longa distâncias dos indivíduos. A instabilidade de armadilhas colocadas a mais de 2,4 $\mathrm{m}$ de altura, em virtude da ação de ventos fortes na região, restringiu o estudo de movimentação a longa distância somente até essa altura máxima.

Diariamente, no período de 9 às 11 horas da manhã, cada armadilha era inspecionada e os indivíduos capturados eram retirados, contados e sexados. O padrão de movimentação foi avaliado com base no número total de cigarrinhas e no número de machos e fêmeas coletados de acordo com a altura, posição geográfica das armadilhas (individual e agrupada por lado da cerca) e fisionomia vegetal nas áreas vizinhas. As comparações foram realizadas utilizando-se a taxa de captura diária, que é representada pelo número médio de adultos (total, machos e fêmeas) capturados por painel e por dia, caracterizando réplicas espaciais e temporais, para altura dos painéis, e laterais, e apenas temporais para cada painel. A razão sexual $\left(\Sigma \varphi \times{ }^{2} \Sigma\left(\sigma^{\prime}+\varphi^{-1}\right)\right.$ também foi utilizada como índice para analisar o comportamento de vôo da espécie.

Visando avaliar se o padrão de movimentação de adultos observado no estudo acima é comum a outras áreas, nove estações de coleta foram montadas em uma área de 
B. ruziziensis medindo 1,4 ha, na Granja do Torto, em Brasília, DF, localizada a cerca de 25 quilômetros de distância da área da Embrapa-CPAC, em dezembro de 1997. As plantas de B. ruziziensis dessa pastagem apresentavam porte inferior a $0,20 \mathrm{~m}$ de altura e a densidade de D. flavopicta na área variou em torno de 18 adultos $/ \mathrm{m}^{2}$ durante as coletas. Essa unidade experimental apresentava uma área de cerrado ao norte da pastagem e pastagens contíguas da mesma espécie nas demais laterais.

O padrão de movimentação de adultos foi comparado, por análise de variância e teste de comparação das médias, utilizando as taxas de capturas diárias dos painéis e considerando a posição dos painéis e as datas de coletas como repetições (Wilkinson, 1990; Kuo et al., 1992).

\section{Marcação e recaptura de adultos para avaliar o pa- drão de dispersão}

A velocidade e o padrão de expansão e movimentação da população de adultos da cigarrinha numa pastagem de B. ruziziensis foi avaliada por marcação e recaptura em uma pastagem na Granja do Torto em janeiro de 1997. Populações de 150 machos e 50 fêmeas foram capturadas, marcadas em todo o corpo com pó luminescente atóxico de diferentes cores e a seguir liberadas. Essa técnica de marcação foi previamente testada com sucesso por Nilakhe \& Buainain (1988). A captura, marcação e liberação foi feita diariamente no início da manhã, durante três dias e também às $14 \mathrm{~h}$ do terceiro dia. Na noite do terceiro dia, quando foi feita a recaptura dos insetos após as $20 \mathrm{~h}$, existiam na área quatro populações marcadas com tintas de diferentes cores respectivas a cada um dos intervalos de liberação (60, 36, 12 e 6 horas). A recaptura foi feita percorrendo-se em faixas toda a área num raio de 50 metros do ponto de liberação, com uma lâmpada do tipo ultravioleta (UV). Devido ao hábito diurno do inseto, que praticamente não se movimenta à noite, aliada à fluorescência provocada pelo efeito da luz UV na tinta, os insetos eram facilmente localizados e capturados manualmente. Baseando-se em observações de que o inseto se movimenta principalmente por meio de saltos baixos e a curta distância (3 a $5 \mathrm{~m}$ ), todos os indivíduos marcados encontrados num raio de $5 \mathrm{~m}$ do ponto de liberação foram considerados como não tendo se movimentado. Os indivíduos recapturados, além dos $5 \mathrm{~m}$ de distância do ponto de liberação, tiveram a posição de recaptura marcada e foram sexados. As distâncias vetoriais e as distâncias nas coordenadas de um plano foram utilizadas para avaliar o padrão de movimentação da população.

\section{RESULTADOS E DISCUSSÃO}

\section{Entrada e saída de adultos da pastagem}

As taxas de captura de adultos nos painéis dispostos na posição baixa foram significativamente maiores do que as obtidas nos painéis na posição alta, em todas as coletas, tanto para machos como para fêmeas (Tabela 1). Os painéis instalados na posição alta, acima de 1,2 m, capturaram apenas 3,7\%

TABELA 1. Comparação da captura média diária de adultos da cigarrinha-das-pastagens (Deois flavopicta) em painéis baixos e altos. Experimento montado em pastagens de Brachiaria na região do Distrito Federal, em dois períodos de observação ${ }^{1}$.

\begin{tabular}{|c|c|c|c|}
\hline Adultos & Baixo (0 a $1,2 \mathrm{~m})$ & Alto $(1,2$ a $2,4 \mathrm{~m})$ & Mann-Whitney \\
\hline & \multicolumn{3}{|c|}{ Período de 19 a 22 de dezembro de 1995 - Face interna } \\
\hline Fêmeas & $3,5 \pm 3,54(52)$ & $0,17 \pm 0,45(39)$ & $1.782 \mathrm{p}<0,001$ \\
\hline \multirow[t]{2}{*}{ Machos } & $6,4 \pm 5,83(52)$ & $0,17 \pm 0,56(39)$ & $1.870 \mathrm{p}<0,001$ \\
\hline & \multicolumn{3}{|c|}{ Período de 19 a 22 de dezembro de 1995 - Face externa } \\
\hline Fêmeas & $1,3 \pm 1,49(39)$ & $0,03 \pm 0,17(23)$ & $1.680 \mathrm{p}<0,001$ \\
\hline \multirow[t]{2}{*}{ Machos } & $3,4 \pm 4,04(39)$ & $0,14 \pm 0,35(23)$ & $1.701 \mathrm{p}<0,001$ \\
\hline & \multicolumn{3}{|c|}{ Período de 9 a 22 de fevereiro de 1996 - Face interna } \\
\hline Fêmeas & $2,6 \pm 3,62(199)$ & $0,18 \pm 0,49(164)$ & $32.402 \mathrm{p}<0,001$ \\
\hline \multirow[t]{2}{*}{ Machos } & $6,4 \pm 5,83(199)$ & $0,40 \pm 0,89(164)$ & $36.681 \mathrm{p}<0,001$ \\
\hline & \multicolumn{3}{|c|}{ Período de 9 a 22 de fevereiro de 1996 - Face externa } \\
\hline Fêmeas & $1,5 \pm 2,34(158)$ & $0,13 \pm 0,47(164)$ & $31.292 \mathrm{p}<0,001$ \\
\hline Machos & $7,8 \pm 7,52(158)$ & $0,30 \pm 0,75(164)$ & $35.055 \mathrm{p}<0,001$ \\
\hline
\end{tabular}

${ }^{1}$ Média \pm desvio-padrão (número de painéis x dias de observação). 
do total de 4.949 adultos coletados nas estações de coleta das laterais da pastagem, em dezembro e fevereiro, na Embrapa-CPAC (Tabela 1). Nilakhe \& Buainain (1988) coletaram entre $80 \%$ e $90 \%$ dos adultos abaixo de 1,0 m de altura, com a razão sexual em torno de 0,40, em pastagens no Mato Grosso do Sul com populações de D. flavopicta, Zulia entreriana Berg. e Mahanarva fimbriolata (Stal). Na região da Bahia, Menezes et al. (1983) observaram que 95\% dos indivíduos coletados são capturados até 1,0 m de altura. Os dados deste trabalho confirmam que o padrão de vôos curtos e baixos é o mais comum.

Nos painéis altos, não foi observada qualquer direção geográfica do campo em que houvesse um maior número de capturas nas diferentes épocas de coleta (Tabela 2), sugerindo que os indivíduos que deixam a área nos vôos mais altos, aqui avaliados, movem-se ao acaso. Não houve diferença significativa no número médio de capturas por dia de fêmeas nos painéis altos voltados para dentro ou fora da área nas coletas de 1995 (Teste de Mann-Witney; $\mathrm{T}=1,39$; $\mathrm{p}=0,41)$ e $1996(\mathrm{~T}=25,6 ; \mathrm{p}=0,46)$. Tal combinação de resultados sugere que, nas condições de baixo porte da pastagem $(0,2$ a $0,5 \mathrm{~m}$ de altura) e densida- des populacionais abaixo de 18 adultos $/ \mathrm{m}^{2}$, os vôos a longa distância não representaram uma forma importante de movimentação das fêmeas de D. flavopicta e, portanto, não são responsáveis por flutuações na população local. Baseando-se na proporção de capturas, pode-se considerar que a principal forma de movimentação dos adultos foi em saltos e vôos baixos, razão pela qual essa forma de movimentação foi analisada de modo detalhado.

A captura nos painéis baixos colocados nas laterais da pastagem não apresentou diferenças significativas quanto à razão sexual dos indivíduos coletados por dia nos diferentes períodos de coleta (Tabelas 3 e 4). A razão sexual do total de insetos capturados foi $0,19(n=4.949)$; portanto, a taxa de captura de machos foi em média aproximadamente quatro vezes maior que a captura de fêmeas. A razão sexual observada em coortes horizontais de D. flavopicta acompanhadas por Sujii (1998) e em criações desta e de outras espécies de Deois (Stoporoli Neto \& Pavan, 1984; Kalvelage \& Buzzi, 1986; Koller \& Honer, 1994) esteve sempre próxima de 0,5 . A diferença entre as razões sexuais observadas nos adultos capturados nas armadilhas, compa-

TABELA 2. Capturas diárias de adultos da cigarrinha-das-pastagens (Deois flavopicta), capturados em armadilhas de painéis com cola em pastagem de Brachiaria ruziziensis na Embrapa-CPAC, Distrito Federal $^{1}$.

\begin{tabular}{|c|c|c|c|c|}
\hline \multirow[t]{3}{*}{ Painel } & \multicolumn{4}{|c|}{ Altura } \\
\hline & \multicolumn{2}{|c|}{ Baixo $(0-1,2 \mathrm{~m})$} & \multicolumn{2}{|c|}{ Alto $(1,2-2,4 \mathrm{~m})$} \\
\hline & Dentro & Fora & Dentro & Fora \\
\hline & \multicolumn{4}{|c|}{ Período de 19 a 22 dezembro de 1995} \\
\hline Norte $(\text { Brachiaria })^{2}$ & $8,75 \pm 7,90(12)$ & $3,50 \pm 3,34(11)$ & $1,71 \pm 1,70(9)$ & $0,14 \pm 0,38(12)$ \\
\hline Sul (Cerrado) & $6,73 \pm 5,73(12)$ & $2,36 \pm 2,01(11)$ & $0,40 \pm 0,55(6)$ & $0,40 \pm 0,55(12)$ \\
\hline Este (Brachiaria) & $16,75 \pm 5,83(12)$ & $5,83 \pm 5,10(10)$ & $0,17 \pm 0,41(8)$ & $0,33 \pm 0,67(12)$ \\
\hline Oeste (Andropogon) & $8,10 \pm 4,82(8)$ & $4,90 \pm 6,19(8)$ & $0,17 \pm 0,49(7)$ & $0,17 \pm 0,41(12)$ \\
\hline \multirow[t]{2}{*}{ Centro } & $14,20 \pm 8,85(10)$ & & $0,50 \pm 0,76(12)$ & \\
\hline & \multicolumn{4}{|c|}{ Período de 9 a 22 fevereiro de 1996} \\
\hline Norte (Brachiaria) & $34,00 \pm 23,2(42)$ & $14,70 \pm 9,6(42)$ & $1,10 \pm 1,4(42)$ & $1,05 \pm 1,7(42)$ \\
\hline Sul (Cerrado) & $3,22 \pm 2,3(36)$ & $2,25 \pm 2,1(36)$ & $0,12 \pm 0,5(42)$ & $0,10 \pm 0,3(42)$ \\
\hline Este (Brachiaria) & $10,30 \pm 8,2(39)$ & $4,35 \pm 4,8(39)$ & $0,10 \pm 0,3(39)$ & $0,17 \pm 0,5(39)$ \\
\hline Oeste (Andropogon) & $17,30 \pm 10,1(41)$ & $14,60 \pm 9,0(41)$ & $0,83 \pm 1,2(41)$ & $0,41 \pm 0,7(41)$ \\
\hline Centro $^{3}$ & $17,00 \pm 9,4(42)$ & & $0,68 \pm 0,9(42)$ & \\
\hline
\end{tabular}

1 Média \pm desvio-padrão (número de repetições).

2 Refere-se ao tipo de vegetação presente na lateral do experimento.

${ }^{3}$ Painéis com cola em apenas uma face. 
TABELA 3. Capturas diárias de adultos da cigarrinha-das-pastagens, Deois flavopicta, em armadilhas do tipo painel com cola em pastagem de Brachiaria ruziziensis na Embrapa-CPAC, Distrito Federal, no período de 19 a 22 de dezembro de 1995. Painéis colocados na face interna da cerca ou no interior da área na posição baixa ( 0 a $1,2 \mathrm{~m}$ de altura) ${ }^{1}$.

\begin{tabular}{|c|c|c|c|c|c|c|}
\hline Painel & $\begin{array}{l}\text { Fêmeas } \\
\text { ( } \overline{\mathrm{X}} \pm \text { d.p. })\end{array}$ & $\begin{array}{c}\text { Machos } \\
(\bar{X} \pm \text { d.p. })\end{array}$ & $\begin{array}{c}\text { Razão } \\
\text { sexual }^{2}\end{array}$ & $\begin{array}{l}\text { Adultos total } \\
(\bar{X} \pm \text { d.p. })^{3}\end{array}$ & Repetições & $\begin{array}{c}\text { Teste } \\
\text { de Dunn }\end{array}$ \\
\hline Norte 1 & $1,50 \pm 1,73$ & $4,75 \pm 3,40$ & 0,21 & $6,25 \pm 4,35$ & 4 & $a b$ \\
\hline Norte 2 & $1,25 \pm 1,89$ & $3,50 \pm 4,36$ & 0,16 & $4,75 \pm 6,24$ & 4 & $\mathrm{~b}$ \\
\hline Norte 3 & $7,75 \pm 5,12$ & $9,25 \pm 2,99$ & 0,44 & $17,00 \pm 6,32$ & 4 & $\mathrm{a}$ \\
\hline Leste 1 & $3,00 \pm 3,16$ & $5,50 \pm 3,87$ & 0,39 & $8,50 \pm 2,65$ & 4 & $\mathrm{a}$ \\
\hline Leste 2 & $5,50 \pm 3,00$ & $12,75 \pm 8,14$ & 0,35 & $18,25 \pm 10,87$ & 4 & a \\
\hline Leste 3 & $10,00 \pm 4,24$ & $13,50 \pm 7,55$ & 0,45 & $23,50 \pm 10,79$ & 4 & a \\
\hline Centro 1 & $3,75 \pm 3,59$ & $13,50 \pm 3,70$ & 0,19 & $17,25 \pm 7,14$ & 2 & $\mathrm{a}$ \\
\hline Centro 2 & $1,00 \pm 0,00$ & $1,50 \pm 2,12$ & 0,63 & $1,25 \pm 1,89$ & 2 & $\mathrm{~b}$ \\
\hline Centro 3 & $5,50 \pm 4,04$ & $11,50 \pm 7,72$ & 0,32 & $17,00 \pm 8,29$ & 4 & $\mathrm{a}$ \\
\hline Oeste 1 & $2,50 \pm 0,71$ & $7,00 \pm 1,41$ & 0,27 & $4,75 \pm 5,50$ & 4 & $\mathrm{a}$ \\
\hline Oeste 2 & $3,50 \pm 2,12$ & $5,00 \pm 1,41$ & 0,40 & $4,25 \pm 4,92$ & 2 & b \\
\hline Oeste 3 & $3,25 \pm 1,89$ & $6,25 \pm 1,50$ & 0,33 & $9,50 \pm 2,65$ & 4 & $\mathrm{a}$ \\
\hline Sul 1 & $1,25 \pm 0,96$ & $3,00 \pm 0,82$ & 0,28 & $4,25 \pm 0,96$ & 4 & $\mathrm{~b}$ \\
\hline Sul 2 & $1,50 \pm 0,71$ & $3,00 \pm 1,41$ & 0,33 & $2,25 \pm 2,87$ & 2 & $b$ \\
\hline Sul 3 & $3,75 \pm 2,36$ & $7,75 \pm 5,38$ & 0,35 & $11,50 \pm 7,59$ & 4 & $\mathrm{a}$ \\
\hline
\end{tabular}

1 Análise de variância não paramétrica Kruskall Wallis.

2 Razão sexual $\mathrm{H}=11,72 ; 14$ g.l.; $\mathrm{p}=0,629$.

3 Total de adultos por lateral $\mathrm{H}=36,16 ; 14$ g.1.; $\mathrm{p}<0,001$

TABELA 4. Capturas diárias de adultos da cigarrinha-das-pastagens (Deois flavopicta) em armadilhas do tipo painel com cola em pastagem de Brachiaria ruziziensis na Embrapa-CPAC, Distrito Federal, no período de 9 a 22 de fevereiro de 1996. Painéis colocados na face interna da cerca ou no interior da área na posição baixa ( 0 a $1,2 \mathrm{~m}$ de altura $)^{1}$.

\begin{tabular}{|c|c|c|c|c|c|c|c|}
\hline Painel & $\begin{array}{c}\text { Fêmeas } \\
(\bar{X} \pm \text { d.p. })\end{array}$ & $\begin{array}{c}\text { Machos } \\
\text { ( } \bar{X} \pm \text { d.p. })\end{array}$ & $\begin{array}{l}\text { Razão } \\
\text { sexual }^{2}\end{array}$ & $\begin{array}{c}\text { Teste } \\
\text { de Dunn }\end{array}$ & $\begin{array}{l}\text { Adultos total } \\
(\overline{\mathrm{X}} \pm \text { d.p. })^{3}\end{array}$ & Repetições & $\begin{array}{c}\text { Teste } \\
\text { de Dunn }\end{array}$ \\
\hline Norte 1 & $3,57 \pm 1,99$ & $19,07 \pm 8,81$ & 0,16 & $\mathrm{ab}$ & $22,64 \pm 10,46$ & 14 & $a b$ \\
\hline Norte 2 & $3,21 \pm 2,52$ & $18,64 \pm 10,90$ & 0,15 & $\mathrm{ab}$ & $21,86 \pm 12,46$ & 14 & $a b$ \\
\hline Norte 3 & $10,29 \pm 6,29$ & $47,21 \pm 17,22$ & 0,17 & $\mathrm{ab}$ & $57,50 \pm 23,11$ & 14 & $\mathrm{a}$ \\
\hline Leste 1 & $0,62 \pm 1,19$ & $7,77 \pm 3,27$ & 0,08 & $\mathrm{ab}$ & $8,39 \pm 3,80$ & 13 & bcde \\
\hline Leste 2 & $2,23 \pm 2,09$ & $16,54 \pm 6,62$ & 0,10 & $\mathrm{ab}$ & $18,77 \pm 8,25$ & 13 & $\mathrm{ab}$ \\
\hline Leste 3 & $0,15 \pm 0,38$ & $3,54 \pm 1,39$ & 0,04 & $\mathrm{a}$ & $3,69 \pm 1,44$ & 13 & de \\
\hline Centro 1 & $2,93 \pm 1,94$ & $12,57 \pm 4,16$ & 0,20 & $\mathrm{~b}$ & $15,50 \pm 3,59$ & 14 & abc \\
\hline Centro 2 & $2,07 \pm 1,9$ & $18,86 \pm 12,6$ & 0,11 & $a b$ & $20,93 \pm 13,92$ & 14 & $a b c$ \\
\hline Centro 3 & $2,86 \pm 1,79$ & $11,57 \pm 5,69$ & 0,20 & $\mathrm{~b}$ & $14,43 \pm 6,95$ & 14 & bcd \\
\hline Oeste 1 & $4,15 \pm 1,68$ & $18,00 \pm 8,97$ & 0,21 & $\mathrm{~b}$ & $22,15 \pm 9,46$ & 13 & $\mathrm{ab}$ \\
\hline Oeste 2 & $1,79 \pm 1,63$ & $8,43 \pm 4,50$ & 0,17 & $\mathrm{ab}$ & $10,21 \pm 5,38$ & 14 & bcde \\
\hline Oeste 3 & $2,93 \pm 2,37$ & $16,86 \pm 9,49$ & 0,16 & $\mathrm{ab}$ & $19,79 \pm 10,99$ & 14 & $a b c$ \\
\hline Sul 1 & $0,36 \pm 0,50$ & $2,57 \pm 2,10$ & 0,11 & $\mathrm{ab}$ & $2,93 \pm 2,34$ & 14 & e \\
\hline Sul 2 & $0,64 \pm 1,01$ & $2,43 \pm 1,56$ & 0,20 & $\mathrm{~b}$ & $3,07 \pm 1,98$ & 14 & $\mathrm{e}$ \\
\hline Sul 3 & $0,63 \pm 1,06$ & $3,38 \pm 2,20$ & 0,07 & $a b$ & $4,00 \pm 2,88$ & 8 & cde \\
\hline
\end{tabular}

${ }^{1}$ Análise de variância não-paramétrica Kruskall Wallis.

2 Razão sexual H = 40,93; 14 g.l.; p < 0.001 .

3 Total de adultos por lateral $\mathrm{H}=142,62 ; 14$ g.1.; $\mathrm{p}<0,001$. 
rada com a população que emerge das ninfas apóia as observações de campo de que machos e fêmeas de D. flavopicta têm um padrão diferenciado de movimentação.

A diferença de peso e de tamanho médio entre os indivíduos é possivelmente a causa das diferenças nas taxas de captura. Os machos são ligeiramente menores e mais leves do que as fêmeas e apresentam maior mobilidade. Deve-se considerar que essa pode ser uma estratégia de dispersão da espécie baseada na troca de genes entre metapopulações (Begon et al., 1996) por meio da movimentação de subpopulações de machos, enquanto as fêmeas permanecem no mesmo sítio. A diferença na razão sexual observada nas coortes (Sujii, 1998) e nos adultos capturados sugere que, aproximadamente, $60 \%$ dos machos estaria se dispersando e deixando a população local. Estudos de flutuação populacional mostram a ocorrência de extinção local e recolonização de novas áreas (Fontes et al., 1995) associados à intensidade dos danos produzidos pelos adultos à planta hospedeira (Valério \& Nakano, 1987, 1988). Tal comportamento sugere a importância da economia do recurso alimentar para a população que permanece na área, principalmente considerando que o inseto ocorria em manchas de plantas hospedeiras nativas distribuídas no cerrado antes da introdução e plantio extensivo de espécies gramíneas suscetíveis como a Brachiaria (Cosenza \& Naves, 1980). Ao mesmo tempo, a estabilidade da população e a variabilidade genética são, aparentemente, mantidas na região pela dispersão e troca de genes por intermédio dos machos.

Não houve um padrão consistente de maior entrada ou saída de adultos em qualquer direção geográfica da pastagem (Tabelas 2 e 5). A variação na posição dos painéis em que ocorreram as maiores taxas de captura sugere que esses valores estão relacionados com diferenças de densidades nas proximidades dos painéis. Fatores físicos como direção predominante dos ventos (S-SE) e posição do sol parecem não influenciar o padrão de movimentação do inseto.

O número médio de adultos capturados nos painéis baixos do centro da área não diferiu significativamente, quando comparados pelo teste de Dunn $(\mathrm{p}=0,05)$, do número médio capturado nas laterais que faziam divisa com outras áreas de B. ruziziensis e A. gayanus em igual ou maior do que nas laterais em que havia Cerrado além da cerca (Tabelas 3 e 4). Isso sugere a inexistência de uma taxa de movimentação de adultos para fora da área maior do que a taxa observada dentro da área de pastagem, e que a movimentação do inseto ocorre ao acaso.

As taxas de captura de indivíduos deixando a área foram mais baixas na lateral onde a fisionomia vegetal além da cerca da pastagem era Cerrado, sendo nas coletas de 1995 (Tabela 3) e 1996 (Tabela 4) localizadas ao sul, e na coleta de 1997 (Tabela 5), ao norte. Assim, os dados sugerem que a paisagem que o inseto visualiza ao fundo atua como um fator de estímulo, ou inibição, para a movimentação a curta distância.

As proporções de captura na face externa em relação à face interna foram mais altas nas laterais sul e oeste, onde não havia a continuidade da vegetação de Brachiaria, sugerindo que houve o retorno dos indivíduos para a pastagem. Nesse caso, as taxas de perda de indivíduos de uma população local, considerando uma pastagem toda circundada com outro tipo de vegetação, seriam próximas às taxas observadas nessas laterais. Esse fenômeno foi descrito por Garcia \& Altieri (1992) e parece estar relacionado não apenas com a concentração de recurso alimentar, mas também com a facilidade de dispersão do inseto em razão da complexidade estrutural da comunidade de plantas e do padrão de distribuição nas mesmas. A presença de arbustos e árvores parece tornar mais difícil a movimentação do inseto mediante pequenos saltos de até $1 \mathrm{~m}$ de altura, levando-os a preferirem se movimentar de volta para áreas abertas e de vegetação homogênea e baixa.

\section{Velocidade e padrão de movimentação de adultos}

Uma elevada proporção, 224 dos 600 machos $(37,3 \%)$ e 108 das 200 fêmeas $(54,0 \%)$, do total de indivíduos marcados e liberados foi recapturada. Uma proporção superior a $63 \%$ dos insetos recapturados foi coletada num raio de $5 \mathrm{~m}$ do ponto de liberação, e acima de $90 \%$ dos indivíduos recapturados estavam dentro de um raio de $10 \mathrm{~m}$ do ponto de liberação (Fig. 1).

A distribuição de frequiência das distâncias percorridas pelos insetos a intervalos regulares, apa- 
TABELA 5. Capturas diárias de adultos da cigarrinha-das-pastagens (Deois flavopicta) em armadilhas do tipo painel com cola em pastagem de Brachiaria ruziziensis na Granja do Torto, Distrito Federal, no período de 3 a 10 de dezembro de 1997. Painéis colocados na posição baixa (0 a 1,2 m de altura) ${ }^{1}$.

\begin{tabular}{|c|c|c|c|c|c|}
\hline Painel & $\begin{array}{l}\text { Fêmeas } \\
(\overline{\mathrm{X}} \pm \text { d.p. })\end{array}$ & $\begin{array}{l}\text { Machos } \\
(\bar{X} \pm \text { d.p. })\end{array}$ & $\begin{array}{l}\text { Razão } \\
\text { sexual }^{2}\end{array}$ & $\begin{array}{l}\text { Adultos total } \\
(\overline{\mathrm{X}} \pm \text { d.p. })^{3}\end{array}$ & Repetições \\
\hline & \multicolumn{5}{|c|}{ Face interna } \\
\hline Norte (Cerrados) & $3,58 \pm 4,67$ & $0,75 \pm 1,22$ & 0,183 & $4,33 \pm 5,44$ & 8 \\
\hline Leste (B. Decumbens) & $5,50 \pm 5,32$ & $1,00 \pm 1,07$ & 0,248 & $7,38 \pm 6,30$ & 8 \\
\hline Oeste (B. Decumbens) & $6,00 \pm 4,90$ & $1,38 \pm 1,77$ & 0,210 & $6,50 \pm 6,26$ & 8 \\
\hline Sul (B. Decumbens) & $6,75 \pm 5,04$ & $2,13 \pm 3,04$ & 0,165 & $8,88 \pm 6,77$ & 8 \\
\hline \multirow[t]{2}{*}{ Centro (B. Decumbens) } & $5,63 \pm 5,84$ & $1,50 \pm 1,53$ & 0,150 & $8,13 \pm 6,92$ & 8 \\
\hline & \multicolumn{5}{|c|}{ Face externa } \\
\hline Norte (Cerrados) & $3,96 \pm 5,92$ & $0,88 \pm 1,15$ & 0,246 & $4,83 \pm 6,77$ & 8 \\
\hline Leste (B. Decumbens) & $3,63 \pm 2,33$ & $0,50 \pm 0,76$ & 0,103 & $4,88 \pm 4,76$ & 8 \\
\hline Oeste (B. Decumbens) & $4,13 \pm 4,05$ & $0,75 \pm 1,04$ & 0,112 & $4,13 \pm 2,53$ & 8 \\
\hline Sul (B. Decumbens) & $8,75 \pm 2,38$ & $2,38 \pm 1,92$ & 0,213 & $11,13 \pm 7,64$ & 8 \\
\hline
\end{tabular}

1 Teste de Kruskal Wallis.

2 Face interna: razão sexual $\mathrm{H}=0,651 ; 4$ g.1.; $\mathrm{p}=0,957$; face externa: razão sexual $\mathrm{H}=1,722 ; 3 \mathrm{~g} .1$; $\mathrm{p}=0,632$.

${ }^{3}$ Face interna: total de adultos por lateral $\mathrm{H}=7,457 ; 4$ g.l.; $\mathrm{p}=0,114$; face externa: total de adultos por lateral $\mathrm{H}=6,782 ; 3 \mathrm{~g} .1 . ; \mathrm{p}=0,079$

rentemente, não permite o ajuste a uma distribuição aproximadamente normal. Conseqüentemente, o modelo de difusão passiva de insetos em ambientes homogêneos, utilizado por Kareiva (1983), não parece se aplicar às populações de adultos da cigarrinha. Se existe uma distância média constante na qual a população da cigarrinha se desloca a intervalos regulares é provavelmente inferior a $5 \mathrm{~m}$ por dia.

A distribuição espacial dos indivíduos que se moveram para além de $5 \mathrm{~m}$ de distância do ponto de liberação é apresentada na Fig. 2. A comparação das distâncias médias percorridas a cada intervalo de tempo (Tabela 6) indica que não há diferenças significativas entre o número de indivíduos recapturados ao longo de diferentes intervalos de tempo entre a liberação e a recaptura, embora tenha havido um aumento progressivo do número de indivíduos dispersos. Não foi possível ajustar a distribuição de distâncias observadas acima de $5 \mathrm{~m}$ a uma distribuição normal. Aparentemente, os insetos estão se movendo ao acaso, não havendo um movimento de difusão que aumente linearmente a distância entre os indivíduos da população.

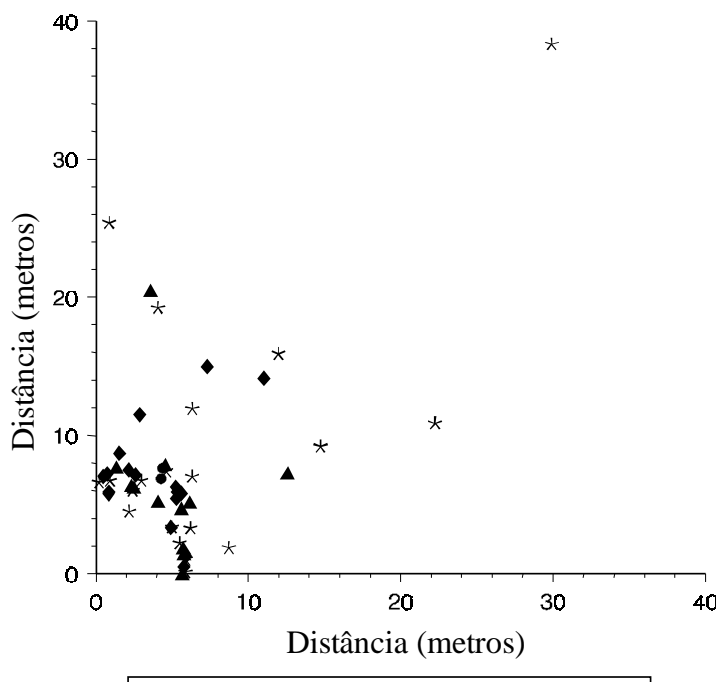

$\bullet 6$ horas $\Delta 12$ horas $\bullet 36$ horas $\star 60$ horas

FIG. 1. Distribuição dos adultos de cigarrinha-daspastagens (Deois flavopicta) marcados com pó luminescente (Bioquip) e recapturados após diferentes intervalos de tempo em pastagem de Brachiaria ruziziensis na região do Distrito Federal.

Pesq. agropec. bras., Brasília, v.35, n.3, p.471-480, mar. 2000 


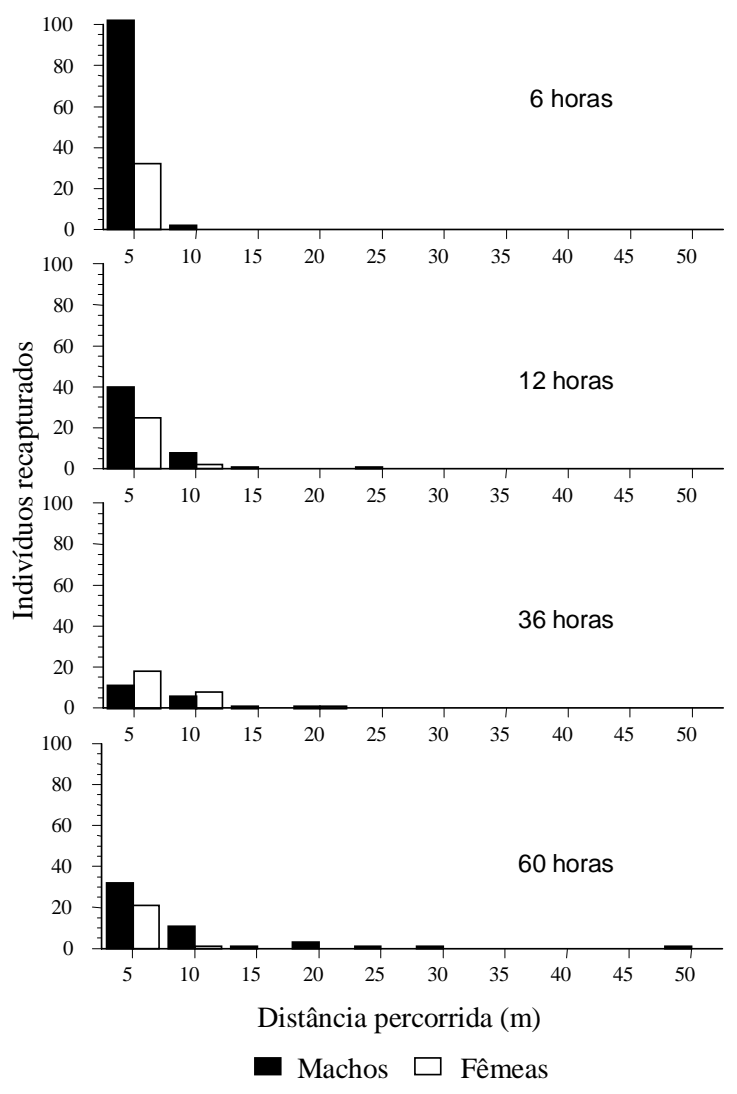

FIG. 2. Adultos de cigarrinha-das-pastagens (Deois flavopicta) marcados com pó luminescente (Bioquip) e recapturados a diferentes intervalos de distância do ponto de liberação em pastagem de Brachiaria ruziziensis na região do Distrito Federal.

A recaptura de fêmeas a uma distância máxima de $10 \mathrm{~m}$ do ponto de liberação, $66 \%$ das fêmeas a menos de $5 \mathrm{~m}$ do ponto de liberação após 36 horas (2 dias) e $100 \%$ após 60 horas (3 dias) apóiam a hipótese de que populações do inseto, principalmente as fêmeas, movem-se a distâncias médias inferiores a $5 \mathrm{~m}$ por dia (intervalos de 12 horas de fotofase) conforme ilustra a Fig. 2. Considerando a longevidade média entre 12 e 30 dias observada por outros autores (Pacheco, 1981; Stoporoli Neto et al., 1985), é razoável supor que, em condições favoráveis e homogêneas de pastagem, as fêmeas mantêm uma área de vida de 50 a $100 \mathrm{~m}$ do ponto onde emergem.
TABELA 6. Distância de deslocamento dos adultos da cigarrinha-das-pastagens Deois flavopicta recapturados a mais de $5 \mathrm{~m}$ do ponto de liberação, após diferentes períodos de tempo em uma pastagem de Brachiaria ruziziensis na região do Distrito Federal ${ }^{1}$.

\begin{tabular}{lcccc}
\hline $\begin{array}{l}\text { Tempo } \\
\text { (horas) }\end{array}$ & $\begin{array}{c}\text { Adultos } \\
\text { recapturados } \\
\text { total }(\%)\end{array}$ & $\begin{array}{c}\text { Distância } \\
\text { tatal } \\
(\mathrm{m})\end{array}$ & $\begin{array}{c}\text { Distância } \\
\text { eixo X } \\
(\mathrm{m})\end{array}$ & $\begin{array}{c}\text { Distância } \\
\text { eixo Y } \\
(\mathrm{m})\end{array}$ \\
\hline 6 & $2(1,0)$ & $8,44 \pm 0,51$ & $4,34 \pm 0,08$ & $7,24 \pm 0,54$ \\
12 & $12(6,0)$ & $8,80 \pm 4,46$ & $5,01 \pm 2,87$ & $6,21 \pm 5,17$ \\
36 & $17(8,5)$ & $8,61 \pm 3,59$ & $4,02 \pm 2,86$ & $6,96 \pm 3,83$ \\
60 & $20(10,0)$ & $12,99 \pm 10,69$ & $7,37 \pm 7,43$ & $9,39 \pm 9,30$ \\
\hline Teste de Kruskal Wallis: & $\mathrm{H}$ & 1,54 & 3,15 & 1,32 \\
& $\mathrm{P}$ & 0,674 & 0,370 & 0,725 \\
\hline
\end{tabular}

${ }^{1}$ Média \pm desvio-padrão.

\section{CONCLUSÕES}

1. A movimentação dos adultos da cigarrinha é predominantemente feita mediante saltos ou vôos baixos (menor de 1,2 m de altura) e curtos que ocorrem ao acaso.

2. A fisionomia da vegetação que compõe a paisagem de fundo, formando áreas abertas como pastagens ou áreas cultivadas, favorece o movimento de saída de adultos; a ocorrência de cerrados ou matas na vizinhança das pastagens inibe o movimento dos insetos nessa direção.

3. A presença de recursos alimentares, para além da divisa da pastagem, altera as taxas de retorno do inseto.

4. Adultos de D. flavopicta, principalmente as fêmeas, mantêm uma área de vida em um raio entre 50 e $100 \mathrm{~m}$ do ponto de emergência como adulto, tendendo a permanecer na mancha de vegetação, caso seja cercada de vegetação de porte arbustivo ou arbóreo.

5. O movimento de dispersão de adultos nas pastagens não contribui significativamente para a perda ou recrutamento de adultos quando as populações locais de D. flavopicta encontram condições favoráveis de recursos alimentares.

6. A movimentação de adultos por dispersão não necessita ser considerada na modelagem da dinâmi- 
ca populacional do inseto, a não ser em casos de explosões populacionais, que provoquem exaustão do recurso alimentar e extinção local do inseto, ou em casos de colonização recente com a implantação de pastagens susceptíveis ao ataque da cigarrinha.

\section{AGRADECIMENTOS}

A Cristiane Avelar, Andrea Serafini, Márcia Lemos, Fernanda Gangana, J. Sávio Paes, Cleber Depieri e Carmen Pires, pela ajuda na montagem dos experimentos e coleta dos dados; a Claudia Jacob, João Frederico Meyer e Robert O’Neil, pelas sugestões no planejamento do estudo; a Bonifácio Magalhães e Miguel Borges, pela revisão do trabalho; e à Embrapa e ao CNPq, pelo apoio financeiro.

\section{REFERÊNCIAS}

BEGON, M.; HARPER J.L.; TOWNSEND, C.R. Ecology: individuals, population and communities. 3.ed. Oxford : Blackwell, 1996. 1068p.

CARNEIRO, M.F.; CUNHA, H.F. da. Avaliação de danos e controle da cigarrinha-das- pastagens (Deois flavopicta) na cultura do milho. Goiânia : EMGOPA, 1984. 14p. (EMGOPA. Boletim de pesquisa, 7).

COSENZA, G.W.; NAVES, M.A. O controle da cigarrinha das pastagens. Brasília : EmbrapaCPAC, 1980. 4p. (Embrapa-CPAC. Comunicado técnico, 6).

FONTES, E.M.G.; PIRES, C.S.S.; SUJII, E.R. Mixed riskspreading strategies and the population dynamics of a Brazilian pasture pest, Deois flavopicta. Journal of Economic Entomology, v.88, n.5, p.1256-1262, 1995.

GARCIA, M.A.; ALTIERI, M.A. Explaining differences in flea beetle Phyllotreta cruciferae Goeze densities in simple and mixed broccoli cropping systems as a function of individual behavior. Entomologia Experimentalis et Applicata, v.62, p.201-209, 1992.

KALVELAGE, H.; BUZZI, Z.J. Ciclo de vida da cigarrinha Deois schach (Homoptera: Cercopidae) a duas temperaturas. Anais da Sociedade Entomológica do Brasil, v.15, n.1, p.113-136, 1986.
KAREIVA, P.M. Local movement in herbivorous insects: applying a passive diffusion model to mark-recapture field experiments. Oecologia, v.57, p.322-327, 1983.

KOLLER, W.W.; HONER, M.R. Desenvolvimento e sobrevivência de ninfas da cigarrinha-das-pastagens (Homoptera: Cercopidae) sobre plantas de Brachiaria decumbens com diferentes características morfológicas. Anais da Sociedade Entomológica do Brasil, v.23, n.2, p.163-170, 1994.

KUO, J.; FOX, E.; MACDONALD, S. Sigmastat: statistical software for working scientists. User's manual. San Francisco : Jandel Scientific, 1992.

MENEZES, M. de; EL-KADI, M.K.; PEREIRA, J.M.; RUIZ, M.A.M. Bases para o controle integrado das cigarrinhas das pastagens na região sudeste da Bahia. Ilhéus : CEPLAC-CEPEC, 1983. 33p.

NILAKHE, S.S.; BUAINAIN, C.M. Observations on movement of spittlebug adults. Pesquisa Agropecuária Brasileira, Brasília, v.23, n.2, p.123134, 1988.

NILAKHE, S.S.; SILVA, A.A. da; CAVACCIONE, I.; SOUZA, A.R.R. Cigarrinhas-das-pastagens em cultura de arroz e sugestões para o seu controle. Campo Grande : Embrapa-CNPGC, 1984. 6p. (Embrapa-CNPGC. Comunicado técnico, 24).

PACHECO, J.M. Aspectos da biologia e ecologia de Deois flavopicta (Stal, 1954) (Homoptera: Cercopidae) na região de São Carlos. São Paulo : UFSCar, 1981. 111p. Tese de Doutorado.

RABB, R.L.; STINNER, R.E. The role of insect dispersal and migration in population process. In: WORKSHOP RADAR: INSECT POPULATION ECOLOGY AND PEST MANAGEMENT, 1978, Virginia, EUA. Proceedings. Virginia : NASA, 1978. p.3-14. (NASA. Conference publication, 2070)

SANTOS, P.J.; CRUZ, I.; BOTELHO, W. Avaliação de dano e controle das cigarrinhas-das-pastagens em plantas de milho com diferentes idades. Sete Lagoas : Embrapa-CNPMS, 1982. 9p. (EmbrapaCNPMS. Pesquisa em andamento, 2).

STOPOROLI NETO, A.; PACHECO, J.M.; MOTTA, L.; PAVAN, C. Métodos de obtenção de ovos de cigarrinhas-das-pastagens Deois spp. (Homoptera: Cercopidae). Revista Brasileira de Entomologia, v.29, n.3/4, p.523-533, 1985.

Pesq. agropec. bras., Brasília, v.35, n.3, p.471-480, mar. 2000 
STOPOROLI NETO, A.; PAVAN, C. Novo método de criação de cigarrinhas-das-pastagens (Homoptera: Cercopidae). Pesquisa Agropecuária Brasileira, Brasília, v.19, n.10, p.1185-1196, 1984.

SUJII, E.R. Modelagem e simulação da dinâmica populacional da cigarrinha-das-pastagens, Deois flavopicta (Homoptera: Cercopidae). Campinas : UNICAMP, 1998. 239p. Tese de Doutorado.

SUJII, E.R. Padrão de distribuição das populações anuais e modelo fenológico para o manejo da cigarrinha-das-pastagens, Deois flavopicta (Homoptera: Cercopidae). Campinas : UNICAMP, 1994. 77p. Tese de Mestrado.
VALERIO, J.R.; NAKANO, O. Danos causados pelo adulto de cigarrinha-das-pastagens Zulia entreriana (Berg, 1879) (Homoptera: Cercopidae) em plantas de Brachiaria decumbens Stapf mantidas em diferentes níveis de umidade. Anais da Sociedade Entomológica do Brasil, v.16, n.2, p.341-350, 1987.

VALERIO, J.R.; NAKANO, O. Locais de alimentação e distribuição vertical de adultos da cigarrinha Zulia entreriana (Berg, 1879) (Homoptera:Cercopidae) em plantas de Brachiaria decumbens Stapf. Anais da Sociedade Entomológica do Brasil, v.17, n.2, p.519-529, 1988.

WILKINSON, L. SYSTAT: The system for statistics. Evanson, Illinois : SYSTAT, 1990. 676p. 